1 Nota do autor: Agradeço a Malcoln Quantrill e a Texas A\&M University pela oportunidade de aposentar este trabalho no "Rowlett Lectures" de 1985. Trata-se do mesmo documento, acrescido de pequena revisão, publicado no folheto editado por Quantrill, "Putting Modernism ie Place, Rowlet Report 85" (College Station, Texas: Texas A\&M University, 1985), pp. 27-32. Logo após a palestra no Texas, tive o prazer de explorar melhor esse material em um seminário patrocinado pela St. Botolph Foundation, no St. Botolph Club, em Boston. Seminário esse organizado pelo recentemente falecido, sábio e querido Roy Lamson, então Professor Emérito de Literatura do Instituto de Tecnologia de Massachusetts. Este ensaio foi publicado no Assemblage 2 (Fev. 1987), pp. 19-31, e revisto em 1706-89.

2 A tradução foi originalmente publicada nos Anais do 40. SEDUR Seminário sobre Desenho Urbano no Brasil, promovido pela Faculdade de Arquitetura e Urbanismo da Universidade de Brasília, Brasília, em 1995.

3 Prêmio CICA 1985 ganho por Klotz pelo "melhor catálogo de exposições de arquitetura".

\section{A FICÇÃO DA FUNÇÃO ${ }^{1}$}

Stanford Anderson

À memória de Ray Lamson

Tradução: Hélia de S. C. Ramos ${ }^{2}$

1 polêmica do pós-modernismo insiste na centralidade e na ingenuidade do conceito de função dentro da Aquitetura moderna. É o erro e a inutilidade desta posição pós-moderna que pretendo revelar. $O$ título que dei a este trabalho, "A Ficção da Função", pode dar a entender que se trata de uma avaliação simplista e negativa do papel da função no processo de criação na Arquitetura. Ao contrário, desejo revelar várias referências possíveis e pertinentes, que podem ser extraídas desse titulo - referências que serviram bem à Arquitetura, e não apenas nos tempos modernos.

Talvez eu deva admitir imediatamente que fui atraído para este assunto pelo tema de uma exposição e um livro de Heinrich Klotz, ambos intitulados Moderno e Pós-Moderno. O slogan de Klotz é "Ficção, não função" - uma evocação efetiva de sua tese de que a distinção entre moderno e pós-moderno pode ser encontrada na substituição do enfoque de função para ficção. Segundo Klotz, essa é também uma distinção normativa, que justifica o apoio da Arquitetura pósmoderna em oposição a qualquer forma de continuidade com a moderna. Não é novidade a classificação da Arquitetura moderna como funcionalista para propósitos polêmicos, e é de admirar que seja necessário abordar a questão novamente. Entretanto, a associação exagerada de modernismo com funcionalismo é freqüente, e, recentemente, o catálogo de Klotz recebeu o prêmio do Comitê Internacional de Críticos de Arquitetura. ${ }^{3}$

Utilizarei o argumento de que "funcionalismo" é um conceito fraco, inadequado à caracterização ou análise de qualquer Arquitetura. Em seu uso freqüente como princípio definidor da Arquitetura moderna, o funcionalismo tem obscurecido nosso conhecimento dessa fase da Arquitetura, tanto da teoria quanto da prática. Além disso, se alguém deseja rejeitar a Arquitetura moderna, como tantos ora propõem, isso é feito sem o conhecimento adequado sobre o quê está sendo rejeitado ou o que essa rejeição impõe.

Assim, pretendo, em primeiro lugar, argumentar que, dentro da Arquitetura moderna, o funcionalismo é uma ficção - ficção no sentido de erro. Em seguida, desejo incorporar a função dentro de uma noção mais rica da ficção - a literária. 


\section{A Ficção da Função no Movimento Moderno observado a partir de 1932}

Para enfraquecer a noção de funcionalismo dentro da Arquitetura moderna, podemos retornar a um tópico que é hoje, talvez, bastante familiar: a exposição e o livro intitulados $O$ Estilo Internacional, organizado por Henry-Russel Hitch-cock e Philip Johnson para o Museu de Arte Moderna de New York em 1932. Não há dúvidas de que é possível exagerar a importância da exposição do Estilo Internacional, embora devamos admitir sua excessiva influência na compreensão da Arquitetura moderna. "O Estilo Internacional", termo criado para a exposição com o objetivo de classificar um grupo de trabalhos excepcionais e criativos da década de 20, impôs-se a ponto de hoje encontrarmos dificuldades para nos referirmos aos trabalhos modernistas daquele período utilizando qualquer outro nome. Pior, o grupo limitado de construções exibidas em New York e os pobres conceitos da exposição do Estilo Internacional continuam a impor severos limites ao que conhecemos dos anos 20 , sem mencionar as restrições à extensão do acervo da Arquitetura moderna para a década de 30 .

Na essência da polêmica de Hitchcock e Johnson, havia um exercício de conhecimento. Os autores procuraram definir os traços visuais que assegurassem à comunidade a verdadeira arquitetura moderna e, conseqüentemente, estabelecessem um estilo, o primeiro estilo próprio desde o Neoclassicismo. A arquitetura moderna não apenas conquistou seu lugar de honra. Isso tudo estava aparentemente concluído, a despeito dos extraordinariamente inadequados critérios estilísticos oferecidos: volume em lugar da massa; regularidade em lugar da simetria; e a evitação do ornamento.

Um importante corolário da ênfase de Hitchcock e Johnson na primazia do estilo foi a rejeição do "funcionalismo". Dentro da Arquitetura progressista da década anterior, eles distinguiram os trabalhos de arquitetura que eram funcionalistas daqueles que não eram. É verdade que havia aqueles arquitetos das décadas de 20 e de 30 que estavam preparados para levantar a bandeira do funcionalismo e para opor resistência a discussões sobre a forma, deixando o "estilo" de lado. Para Hitchcock e Johnson, o monstro do funcionalismo era Hannes Meyer, que, em seus tempos de Bauhaus, construiu diagramas de circulação e luz solar, que pretendiam mostrar os "Fatores que determinam um projeto". Longe do funcionalismo ser o ponto central da Arquitetura moderna, foi precisamente a evitação 
do funcionalismo, conforme admitido por Hitchcock e Johnson, que permitiu sua inclusão sob as asas do Estilo Internacional. Dir-se-ia que os criadores do Estilo eram, sem dúvida, Ludwig Mies Van der Rohe, Walter Gro-pius, J.J.P. Oud e Le Corbusier.

A insistência de Hitchcock e Johnson no estilo pode ter delineado um limite entre certas fases da Arquitetura moderna, como por exemplo entre o funcionalismo aparente de Meyer e a sofisticação de Mies, na casa de Tugendhat, de 1930. Mas essa linha limítrofe não é a marca de inclusão ou exclusão da exposição do Estilo Internacional. Se tornarmos a polêmica dos autores contra o funcionalismo como o ponto focal de seu trabalho, teremos que reconhecer que alguns dos arquitetos incluídos não teriam se sentido desconfortáveis com sérias discussões sobre a função. Considere-se os estudos de Gropius sobre a densidade das casas de Zeilenbau, de acordo com um critério do ângulo do Sol ou as casas de Siemensastadt, que são organizadas inexoravelmente como quaisquer habitações de um chamado funcionalista. Por outro lado, se tomarmos como ponto central os critérios visuais dos autores para fazerem parte do "Estilo Internacional", seremos seriamente pressionados a entender a exclusão desses autores da competição da Liga das Nações pelo arquifuncionalista Hennes Meyer (que facilmente preenche todos os critérios do Estilo Internacional) e a aceitar o Pavilhão de Barcelona, de Mies (o qual, se não está preocupado com a massa, também não está com o volume). Além disso, devemos reconhecer que alguns dos heróis de Hitchcock e Johnson nunca se sentiram à vontade com o empreendimento do "estilo", certamente não com o empreendimento pobre e formal proposto no Estilo Internacional.

Mais importante que esses primeiros pontos sobre a demarcação de limite tentada por Hitchcock e Johnson é a distorção que sua posição introduz em qualquer análise do pensamento e do trabalho dos arquitetos progressistas daquele período. Pode ser útil reconhecer o "funcionalismo" a ponto de se poder encontrar alguns argumentos funcionalistas ingênuos que contrastam com a retórica anti-funcionalista de Hitchcock e Johnson. Entretanto, qualquer exame sério das construções em questão revelará que nenhuma delas, qual-quer que seja a retórica do momento, pode ser explicada funcionalmente. Era ficção afirmar que a função impunha uma linha crucial de demarcação dentro da Arquitetura moderna. 


\section{A Ficção Pós-Guerra da Função no Movimento Moderno}

Em carta enviada ao Instituto Real de Arquitetos Britânicos em 1957, o renomado historiador de Arquitetura, John Summerson, argumentou que o funcionalismo, no sentido de fidelidade ao programa, forneceu o princípio de unificação da Arquitetura Moderna. De acordo com ele, a função tornou-se não apenas um tratado comum, mas também positivo da Arquitetura moderna (embora haja um sentimento de que Summerson aceitou este fato um tanto fatalistamente). Os arquitetos modernos que responderam a Summerson aceitaram suas reivindicações, na melhor das hipóteses, com alguma desconfiança. O próprio Summerson desmentiu logo sua hipótese, mas a equiparação de modernismo com funcionalismo continua a existir. Os defensores do chamado "pós-modernismo" adotaram a posição ainda mais insustentável de que é uma linha de demarcação funcionalista que separa todos os modernismos das posições sucessoras. Eles estigmatizam todo o modernismo como funcionalismo; a ingenuidade e/ou a inadequabilidade do funcionalismo é forçosamente discutida; a rejeição racional do funcionalismo implica, então, na rejeição do modernismo.

C.Q.D.

Mas, se era ficção considerar o funcionalismo como característica principal mesmo de apenas parte do modernismo, é uma ficção mais grave considerar todo o modernismo como funcionalista. Essa ficção é utilizada para definir o modernismo de forma limitada e em termos indefensáveis e, assim, denegrir o modernismo. Uma vez que o pós-modernismo é tipicamente definido não em seus princípios, mas em oposição ao modernismo, a mais limitada e inadequada caracterização do modernismo oferece a mais fácil vitória sobre o modernismo e o mais amplo campo para o pósmodernismo.

\section{A Ficção Inerente à Função na Arquitetura}

Nenhuma descrição de função, por mais completa que seja, é exaustiva com relação às características funcionais das atividades, mesmo que relativamente simples. A inadequação dos parcos fatores definidos por Hannes Meyer para determinação de um projeto não pode ser resolvida pela adição de mais fatores.

Nenhuma descrição de função, por mais completa que seja, se traduz automaticamente em forma de arqui- 
tetura. Quanto mais completa a descrição de função, menos provável que essa descrição permaneça válida, mesmo para o período de duração do processo de desenho.

Seria difícil, se não impossível, encontrar um artefato, simples ou complexo, que não tenha funcionado de modo imprevisto. A partir de argumentos como esses, suponhamos que o funcionalismo seja uma posição insustentável. Se for, então será razoável para o pósmodernismo não ser funcionalista. Entretanto, pela mesma razão, afirmo que poucos modernistas tiveram sequer intenções funcionalistas. Contudo, mesmo que o funcionalismo ofereça uma análise injusta da Arquitetura, ele não parte do princípio de que toda a preocupação com a função seja errada, nem de que a abordagem totalmente anti-funcionalista é correta.

\section{Histórias sobre a Função}

Se o funcionalismo é inerentemente uma ficção, quaisquer pretensões de funcionalismo no movimento moderno deve ser uma ficção. Isso é verdade, porém, em mais de um sentido. E a ficção nos dois sentidos que já mencionei: a) nem mesmo os funcionalistas assumidos poderiam de fato preencher seus programas sem recorrer a outros geradores de formas; b) nem todos os modernistas, sem dúvida muito poucos, jamais endossaram o funcionalismo. Entretanto, uma preocupação com a função poderia também ser uma ficção dentro de uma conotação mais positiva da palavra, no sentido literário e não de falsidade.

A arquitetura é, entre outras coisas, um suporte do significado, conforme os pós-modernistas nos dirão. No entanto, isso não era menos verdadeiro no modernismo do que em outros períodos. Além disso, não é, certamente, exclusividade da arquitetura moderna que parte da sua história seja sobre a função. Deve-se admitir, entretanto, que a arquitetura moderna, mais do que qualquer outra, enfatizou histórias sobre a função.

Os fragmentos de tais histórias podem ser carregados mesmo em detalhes um tanto óbvios: prova direta das características funcionais de um edifício, como na diferenciação de janelas em escadas ou espaços amplos; ou elementos do edifício desenhados para revelar a função da construção, como quando as amplas janelas mostram máquinas impressoras ou outras instalações mecânicas. 
Certas características dos edifícios podem revelar as funções internas tão diretamente que podem ser vistas como mais do que metáforas dessas funções: a extensão e a repetividade do desenho de uma fábrica apresenta características similares dos processos que ela abriga.

Os detalhes estruturais podem revelar sua própria função, mas podem também ter sentido metafórico: as grandes junções de pinos dos arcos da Fábrica de Turbinas de Peter Behrens, em Berlim, belamente trabalhadas e exibidas em pedestais logo acima do nível da rua, insistem em sua própria objetividade, ao mesmo tempo em que representam as engrenagens de seu próprio sistema estrutural e cognatos às engrenagens de um outro sistema mecânico fabricado ali mesmo.

Por essa razão, é virtualmente impossível privar os elementos do edifício das qualidades metafóricas associadas a várias funções: portais e portas carregados com o significado de entrada e saída; janelas como se fossem os olhos dos edifícios ou a estrutura através da qual é proporcionada uma visão controlada do mundo. No entanto, todos esses exemplos, quando tomados isoladamente ou em agrupamentos casuais, não passam de anedotas. Somente quando um construtor ou arquiteto tem uma visão mais ampla de seu trabalho e faz esses detalhes individuais, às vezes inevitavelmente metafóricos, alcançarem um nível mais alto de organização é que nós podemos chamar de ficção, história. Essa história pode ser sobre função, e não apenas a função literal do trabalho.

Talvez nenhum trabalho tenha sido considerado tão pura demonstração da tese do funcionalismo como as cozinhas desenhadas para as casas de Frankfurt sob a direção de Ernst May, no final da década de 20. A "Frankfurter Küche" (Cozinha de Frankfurt), assim como a da fazenda Romerstadt, está evidentemente relacionada com a economia, no tamanho e na organização, ainda que tal observação seja apenas superficial. A cozinha deve também ser vista em seu contexto político e social. Graças a toda sua economia, essa cozinha oferece mais do que tem estado disponível para alguns dos residentes e faz parte de um programa criado para assegurar o ambiente adequado a todos em uma situação de recursos econômicos limitados. Além disso, sua economia é avaliada não somente em termos de tamanho da cozinha, mas também em uma reavaliação do papel da cozinha no lar e na sociedade. Pode-se endossar ou não a vida imaginada aqui, mas imaginada eloqüentemente ela o foi, não constituindo a obra apenas uma pequena coisa bela. 
O que pode ser considerado funcionalismo nas projeções de oficinas da Bauhaus, de Gropius, em Dessau, está muito mais profundamente ligado à metafísica modernista da desmaterialização adotada por Laszlo Moholy-Nagy em suas construções e em suas aulas.

Ozenfant e Le Corbusier conceberam o Esprit Nouveau, uma interpretação de qualidade de vida que estava surgindo ou era latente, em face das condições dos tempos modernos. A mesma visão denuncia a vida tranqüila de Le Corbusier, a ingenuidade espacial e formal da Villa Savoye, ou, ainda, novamente a percepção seletiva da cozinha daquela mesma casa de campo. Le Corbusier proporcionou uma visão de certos produtos eternos; o pão, a lata de leite, a garrafa de vinho, luz e ar, acesso à terra e ao céu, saúde física, tudo colocando à disposição mais completamente e em maior quantidade, graças aos novos potenciais espirituais e técnicos. São raros os detalhes da Villa Savoye qua não contribuem para esta história. O pavillon de l'Esprit Nouveau e os immeubles villas contam a mesma história, com mais economia, procurando tomar os mesmos produtos mais generosamente disponíveis.

\section{A Criação de um Mundo}

O fato de a Villa Savoye nos contar uma visão que Le Corbusier teve, é sem dúvida uma história. Assim, penetramos na dimensão iconográfica da arquitetura. Por mais que a Villa Savoye permita que vivamos de acordo com aquela visão, ocorre algo mais. Ela "cria um mundo" que não determina, mas permite-nos viver e pensar diferentemente do que se não existisse. Se essa ficção pode apenas existir precariamente na Villa Savoye, ela pode, sem dúvida, ser "meramente" uma ficção, tão valiosa para nós como outras grandes histórias. Se sua visão ou princípios podem ser generalizados, podemos ter um domínio literal sobre um mundo que não poderia ter sido nosso sem a ficção originária.

Afastamo-nos muito das noções limitadas de função com as quais iniciamos. Contudo, proporcionar as condições físicas possíveis para uma forma de vida é tratar a função no seu mais alto nível, e os detalhes ou referências mais limitados podem permanecer intactos quando se tratar de tão grande pretensão.

Não há apenas um caminho que essas pretensões maiores possam seguir. A cada vez que Louis Kahn procurou reconceber uma instituição e dar a ela os contor- 
nos físicos que a permitissem alcançar completamente seu potencial, ele "criou um mundo" naquele lugar para aquele grupo de pessoas, mas também nos informou sobre os princípios e o desempenho específico.

Alvar Alto fez o mesmo muitas vezes, mas com diferenças importantes no "mundo" que vislumbrou. É um mundo no qual as várias instituições são menos diferentes umas das outras e compartilham mais entre si. Há menos controle institucional. Há mais da complexidade e da fusão do natural com o artificial, do novo com o velho. Um aspecto importante e muito pouco explorado de Aalto é sua preocupação constante em identificar uma reciprocidade entre "seu mundo" e o mundo. "Seu mundo" foi puxado de volta do idealismo utópico e informado pelas condições do mundo em sua volta. Uma razão e ao mesmo tempo um fruto dessa restrição foi a recusa de Aalto em renunciar a ambição de fazer o mundo melhor e não apenas para os privilegiados. Durante e após o longo período de guerra da Finlândia, Aalto esteve preocupado com o aperfeiçoamento das moradias convencionais sob severas restrições. Em comparação com o Esprit nouveau, ou mesmo com os trabalhos mais famosos de Aalto, essa foi uma história modesta, não obstante a criação de um mundo, que vai além da tarefa literal. Exatamente a forma e o grau em que esses trabaIhos mais modestos de Aalto superam o convencional, suscita questões semelhantes àqueles explorados por Adolf Loos no início do século em Viena.

Loos, Le Corbusier, Kahn, Aalto. Sobre cada um desses arquitetos podem surgir muitas manifestações. Na especificidade da criação arquitetônica, eles criaram lugares que "criam um mundo", diferentes e, sem dúvida, mutuamente insustentáveis, nenhum dos "mundos" concebidos por eles pode ser confundido com meros caprichos do design, que oferecem apenas conforto passageiro ou rápidas palpitações a consumidores de arquitetura. Suas construções contam histórias, mas não apenas uma história qualquer, diferente, interessante, irônica ou elaborada para ser vendida. Correta ou erroneamente, não sombriamente, mas com amplo reconhecimento das potencialidade e das alegrias da vida e da arquitetura, eles desafiaram a si mesmos a descobrir como a arquitetura poderia servir a seus contemporâneos. Fazer o que fizeram envolve não a função ou ficção, mas ambas e muito mais. O trabalho exigiu deles um envolvimento total com a arquitetura e a vida que ela prestigia e à qual se dedica.

Eu afirmaria que arquitetos como Loos, Le Corbusier, Aalto e Kahn procuraram "colocar o modernismo em seu lugar", ou melhor, proporcionar ao modernismo 
4 Adolf Loos, conforme referência de Heinrich Kulka, "Adolf Loos, 1870-1933", Architects Yearbook 9 (1960), p. 13.

5 A defesa de Le Corbusier da Arquitetura contra o funcionalismo é conhecida através de sua resposta ao critico de Czech, Karel Teige, em 1929. Le Corbusier confronta as palavras dos funcionalistas, embora os reconheça como poetas contemporâneos por seus trabalhos. A opinião de Teige-Le Corbusier está disponível em inglês no Oppositions 4 (Outubro 1974), pp. 79-108. um lugar. Loos falou da "criação de edifícios nos quais se pudesse desenvolver uma forma moderna de vida". 4 Gosto dessa formulação, por abrir espaço entre o lugar oferecido e a vida vivida. Em conseqüência, ela dissipa qualquer senso de determinismo da arquitetura sobre a vida moderna ou vice-versa. Em suas construções, Le Corbusier, em comparação a Loos, projetou mudanças mais radicais, tanto na arquitetura quanto na vida moderna - tranqüila, acredito, sem determinismos. Sua machine à habiter, é uma peça provocante em uma construção francesa repetitiva, a "máquina para se habitar" que apresenta novas condições, porém não mais determina como a vida será vivida, como a machine à écrire determina o que será escrito. ${ }^{5}$

Em seus trabalhos, os arquitetos aqui citados procuraram criar lugares que sustentassem as ficções modernas. Da mesma forma, podemos assumir uma posição para historiadores ou críticos: a necessidade de oferecer uma história adequada sobre a arquitetura moderna, se vamos criticá-la e crescer com essa critica.

Dificilmente pareceria necessário fazer uma reivindicação à primeira vista tão banal, mas o é, aparentemente. Quando uma rejeição intelectualizada do funcionalismo pode ser usada para rejeitar a arquitetura moderna e para evitar uma compreensão mais integral da arquitetura incluindo a função; quando a capacidade iconográfica da arquitetura pode ser isolada como a característica dominante da arquitetura e toda a preocupação com o que é comunicado é deixado de lado; quando a arquitetura torna-se comunicação em vez de lugar, lugar relacionado com responsabilidades e potencialidades comunitárias; então nós precisamos retornar a um discurso mais crítico. Apenas trabalhos fortes o suficiente para desafiar-nos facilitam tal discurso.

\section{Referências}

KLOTZ, Heinrich. Moderna und Postmodeme Architektur der Gen-genwart 1960-1980. Braunschweig: Vieweg \& Sohn, 1984.

HITCHCOCK, Henry-Russel; JOHNSON, Phillip. The International Style: Architecture since 1922. Princeton: W.W. Norton \& Co., 1932

SUMMERSON, John. "The Case for a Theory of Modern Architecture", Journal of the Royal Institute of British Architects, ser. 3, vol. 64, June 1957, pp. 307-314. 